ORIGINAL ARTICLE

\title{
Contraceptive Practice of Married Women: Experience from a Rural Community of Bangladesh
}

\author{
*A Rahman ${ }^{1}$, M Rahman ${ }^{2}$, S Huq ${ }^{3}$, S M Hossain ${ }^{4}$ \\ ${ }^{1}$ Dr. Md. Atiqur Rahman, Assistant professor, Dept. of Community Medicine, AKMMC. \\ ${ }^{2}$ Prof. Dr. Md. Mahfuzar Rahman, Professor and Head Dept. of Community Medicine, AKMMC \\ ${ }^{3}$ Dr. Sazia Huq, Lecture, Northern University of Bangladesh (NUB) \\ ${ }^{4}$ Dr. (Lt.Col) Sardar Mahmud Hossain, Professor and Head, Dept of Public Health, NUB \\ *Corresponding author
}

\begin{abstract}
Bangladesh is a country having high density of population in the world. Its fertility rate ranges from 4.1 to 5.49 and life expectancy is 66years while the total fertility rate of Asia is 2.2 and life expectancy 70 years. This descriptive type of cross sectional survey was carried out among 240 married women of reproductive age from July to December, 2012 in some villages of Keranigonj, Upazila, Dhaka. 73(31\%) were practicing some methods of contraception, while 167 (69\%) were not using it. OCP (Oral Contraceptive Pill) was the commonest method of contraception followed by Condoms 12(5\%), Injectable 12(5\%), Implant 12(5\%) \& Tubectomy $6(3 \%)$. None was found using IUCD and Traditional method ( withdrawal, rhythm method ) and emergency contraceptive method. The use of contraceptive was more common in grand multipara $(p<0.01),>35$ years old ladies $(p<0.05)$. Non users of contraceptives in this study were $167(69 \%)$ and the major reason for the non use was intention to have more children $53(31.46 \%)$ followed by pressure from the husband 21(12.35\%), prohibition by the religion 18 $(10.9 \%)$ and desire for son $17(10.11 \%)$. Among the 73 contraceptive users 38 (52\%) experienced side effects with the use of contraceptives. The commonest side effects were menstrual irregularities $17(23.8 \%)$ followed by change in body weight $8(11.19 \%)$. Frequency of contraceptive use was found comparatively low among rural married women despite high level of awareness. Desire for larger family, religious concerns and fear of side effects were the main factors responsible for non users. Religious scholars must play their role in clarifying many aspects regarding contraceptives.
\end{abstract}

Key words: Contraception, Reproductive age, Total fertility rate

\section{Introduction}

A contraceptive method is one which helps the women to avoid unwanted pregnancy resulting from coitus. There are many methods of contraception. Each has got its own merits and demerits. An ideal contraceptive method is one which is safe, effective, acceptable, inexpensive, reliable, reversible, simple, long lasting, independent of coitus and requires less medical supervision. A method suitable for one group may not be suitable for another group because of different cultural background, religious beliefs and socio-economic status. Thus there can never be an ideal contraceptive method ${ }^{1}$.
Of the world population, $75 \%$ live in developing countries characterized by high fertility rates, high maternal and infant mortality and low life expectancy ${ }^{2}$. In the developing world, 1/3rd of all healthy adult women are lost due to reproductive health problem ${ }^{3}$. Female population is about 60.26 million in Bangladesh and married women of reproductive age group constitute $51.7 \%$ of all total female population4. More than 5,00,000 women die every year due to pregnancy related complications in the developing world ${ }^{5}$. Although the average age at marriage is 18 years for females and 27 years 
for males, rural females tends to marry even earlier. Approximately $75 \%$ of the girls are married before the age of 16 and only $5 \%$ are married after 18 years which is the legal age of marriage for females in Bnagladesh6. Like early marriage, early pregnancy is common in Bangladesh. The adolescent fertility rate in the country is one of the highest in the world with 147 birth per 1000 women age < 20 years ${ }^{7}$.

Contraceptive prevalence rate (CPR- which is the proportion of women of reproductive age (15-49 years) who are using or whose partner are using a contraceptive method at a given point in time) is $30 \%$ which was $29 \%$ in 2009 and 2008 while the most developed country like USA has $71 \%$ CPR for all the methods. ${ }^{2,8-10}$

Worldwide the fertility rate ( the total number of children the average women in a population is likely to have based on current birth rates throughout her life) have fallen largely due to the world-wide spread and increasing use of modern methods of contraception. However, in some developing countries like Bangladesh the uptake of contraception remains low due to cultural, economical and political barriers. After nearly five decades of government initiated family planning programs ${ }^{11}$. Total fertility rate in Bangladesh ranges from 4.1 to 5.49 and life expectancy is 66 years while the total fertility rate of Asia is 2.2 and life expectancy 70 years $^{1}$ Though the total fertility has decreased in Bangladesh but still it has the highest rate in south Asia. To understand this problem research is needed to investigate the social, religious and cultural aspect of females. The major myth regarding contraception is that it causes harm to womb and causes sterility ${ }^{12,13}$. Female education and autonomy as well as husband education put a direct impact on the contraceptive prevalence rate. ${ }^{14,15}$

The aim of this study was to find out contraceptive practices of married women in the rural community of Bangladesh. The secondary outcome measures were to compare it according to the age, parity, occupation and educational status of the women as well as education status of their spouse.

\section{Methodology}

This descriptive cross sectional study was conducted during the period of July to December'2012 to assess the contraceptive practice among the married women in some villages of Keranigonj Upazila, Dhaka. The respondents were married women of reproductive age (15-49) and were selected purposively on the basis of selection criteria from rural households of Keranigonj Upazila, Dhaka.

Descriptive statistics were run based on respondent's socio-demographic characteristics, reproductive health problems and contraceptive practices. Odds ratios were calculated to find out the strength of relationship between contraceptive practice and age, parity, occupation and education of the respondent's as well as their husband's education, while chisquare test was used to find out the significance of proportion of contraceptive practiced.

\section{Results}

Among 240 women of reproductive age group (15-49 years), about half $(47.4 \%)$ of the respondents were in the age group 20-30 years. The socio-demographic characteristics of the respondents were described in Table-I. The mean age of the study population was $29 \pm 6.5$ years with the mean age at marriage of $17.18 \pm 2.7$ years.

Of the respondents, $73(31 \%)$ were practicing some methods of contraception, while 167 (69\%) were not using it. OCP( Oral Contraceptive Pill) was the commonest method of contraception, followed by Condoms $12(5 \%)$, Injectable 12(5\%), Implant 12(5\%) \& Tubectomy $6(3 \%)$. No one was found using IUCD and Traditional method ( withdrawal, rhythm method ) and emergency contraceptive method. Figure-I

The use of contraceptive was more common in grand multipara $(p<0.01),>35$ years old ladies $(\mathrm{p}<0.05)$. No statistical association was found between the use of contraceptive method and educational status of the respondents and their husband. Table-III

Non user of contraceptive in this study were 167 $(69 \%)$ and the major reasons for the non use 
were Intention to have more children $53(31.46 \%)$, followed by Pressure from the husband 21(12.35\%), Prohibition by the religion $15(10.9 \%)$ and Desire for son 14 (10.11\%). Non-availability of contraceptive was the least common $4(2.4 \%)$ cause for not practicing contraception. ( Table-IV).

Among the 73 contraceptive users 38 (52\%) experienced side effects with the use of contraceptives. The commonest side effects were menstrual irregularities $17(23.8 \%)$ followed by change in body weight $8(11.19 \%)$. Table-V

Table-I: Distribution of respondents by Sociodemographic characteristics $n=240$

\begin{tabular}{|c|c|}
\hline Attribute & Findings \\
\hline Age (in years) & $\begin{array}{l}<20: 10 \%, 20-25: 21.6 \%, 26-30: 25.8 \%, 31-35: 18.3 \\
>35: 24.16 \% ; \quad \text { Mean age }( \pm S D)=2 \quad 9 \pm 6.5 \text { years }\end{array}$ \\
\hline Education (respondents) & $\begin{array}{l}\text { Uneducated:62\%, Below SSC:20. } \quad 4 \%, \text { SSC:8. 3\%, HSC: } 4 \% \text {, } \\
\text { Bachelor:3 .3\%, Master degree:2\% }\end{array}$ \\
\hline Education (Husband) & $\begin{array}{l}\text { Uneducated:30\%, Below SSC:24\%, SSC:25\%, HSC: 10\%, } \\
\text { Bachelor: } 6 \% \text {, Master degree:5 \% }\end{array}$ \\
\hline Monthly income(TK) & $\begin{array}{l}\text { TK<3000:6. } 6 \% \text {, TK } 3001-5000: 22.5 \% \text {, TK } 5001-7000: 38.75 \\
\text { TK } 7001-9000: 26.75 \%, \text { TK }>9000: 5.4 \%\end{array}$ \\
\hline & Average $( \pm S D) \quad: 4550 \pm 1450$ \\
\hline Age at marriage (in years) & $\begin{array}{l}14-17: 63.5 \%, 18 \quad-21: 31.5 \%, 22 \quad-25: 5 \%, \text { Mean age at } \\
\text { marriage }( \pm S D) \quad: 17.18 \pm 2.7 \text { years }\end{array}$ \\
\hline Age at first child (in years) & $\begin{array}{l}15-20: 69.83 \%, \quad 21-25: 29.05 \%, 26 \quad-30: 1.12 \text {, Mean age at first } \\
\text { child } \pm \text { SD) : } 19 \pm 2.6 \text { years }\end{array}$ \\
\hline \multirow[t]{2}{*}{ Number of children } & $<2: 29.5 \%, 2 \quad-5: 49.5 \%,>5: 21 \%$ \\
\hline & Mean number of children \pm SD: $3 \pm 1$ \\
\hline
\end{tabular}

Table-II: Association of age, parity and education of women/husband to contraceptive practice $n=240$

\begin{tabular}{|c|c|c|c|c|c|c|}
\hline Variable & Level/Range & $\mathrm{CP}+$ & $\mathrm{CP}$. & $\begin{array}{l}\text { Chi - } \\
\text { Square }\end{array}$ & $0 \mathrm{R}+95 \% \mathrm{CI}$ & p-ralue \\
\hline \multirow[t]{2}{*}{ Age } & $>35$ years & 25 & 36 & \multirow[t]{2}{*}{5.24} & 2.16 & \multirow[t]{2}{*}{$p<0.05$} \\
\hline & $<35$ years & 48 & 131 & & & \\
\hline \multirow[t]{2}{*}{ Parity } & $>5$ & 24 & 30 & \multirow[t]{2}{*}{6.85} & 2.51 & \multirow[t]{2}{*}{$P<0.01$} \\
\hline & $<5$ & 49 & 137 & & & \\
\hline \multirow[t]{2}{*}{ Educational status } & SSC and above & 16 & 33 & \multirow[t]{2}{*}{1.97} & 1.72 & \multirow[t]{2}{*}{$p>0.05$} \\
\hline & $\begin{array}{c}\text { Be low SSC \& } \\
\text { uneducated }\end{array}$ & 57 & 134 & & & \\
\hline \multirow{2}{*}{$\begin{array}{l}\text { Husband's } \\
\text { educational status }\end{array}$} & SSC and above & 35 & 74 & \multirow[t]{2}{*}{0.92} & 1.34 & \multirow[t]{2}{*}{$p>0.05$} \\
\hline & $\begin{array}{c}\text { Below SSC \& } \\
\text { uneducated }\end{array}$ & 38 & 93 & & & \\
\hline
\end{tabular}

Table-III: Reasons of non uses of contraceptivesn $=167$

\begin{tabular}{lcc}
\hline Reasons & Frequency & Percentage (\%) \\
\hline Desire for children & 53 & 31.46 \\
Pressure from husband & 21 & 12.35 \\
Prohibition by religion & 18 & 10.9 \\
Desire for son & 17 & 10.11 \\
Lack of awareness & 12 & 7 \\
Did not think about it & 12 & 6.9 \\
Pressure from mother in law & 6 & 3.85 \\
Herself did not want & 6 & 3.85 \\
Fear of side effects & 6 & 3.85 \\
Husband is aboard & 6 & 3.85 \\
Lactational ammenorrhoea & 6 & 3.37 \\
Non availability & 4 & 2.4 \\
\hline
\end{tabular}

Table-IV: Side effects of contraceptive use $\mathrm{n}=73$

\begin{tabular}{lcc}
\hline \multicolumn{1}{c}{ Side effects } & Frequency & Percentage (\%) \\
\hline No side effects & 35 & 48.73 \\
Menstrual disturbances & 17 & 23.80 \\
Change in weight & 8 & 11.19 \\
Other effects ( Infections, & 7 & 9.38 \\
backache, feeling of guilt etc) & & \\
Behavioral disturbances & 6 & 6.8 \\
Total & 73 & 100 \\
\hline
\end{tabular}

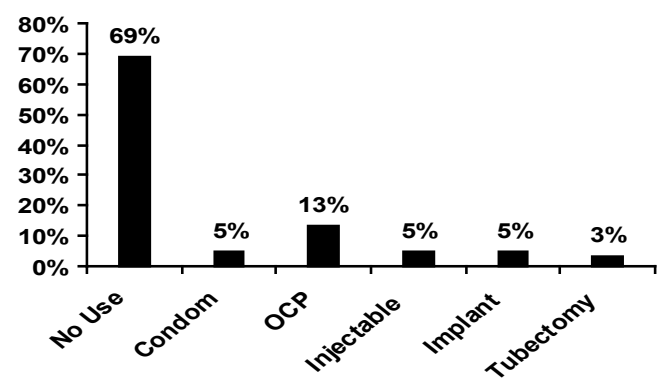

Figure-1: Distribution of respondents by use of contraceptives

Figure 1 shows that $13 \%$ respondents use OCP and $69 \%$ respondents do not use any contraceptives.

\section{Discussion}

Child birth is the leading cause of death among women of reproductive age as one in five women of reproductive age die due to child birth related complications. ${ }^{3}$ In spite of the fact that more than 3000 family planning centers are working in the country, population growth rate is still $1.56 \%$. 
According to Bangladesh Demographic and Health Survey, maternal mortality can be reduced by $36 \%$ if CPR goes up to $55 \% .{ }^{4}$ Despite almost 3 folds increase in contraceptive use since last 20 years, $25 \%$ of the currently married women have an unmet need of family planning services. ${ }^{9}$

Literacy rate in this study was very low. About $62 \%$ respondents were totally uneducated and another $29 \%$ had only primary and middle education. This figure is contradictory to study by Inamullah et $\mathrm{al}^{17}$ and this level of literacy may not reflect the true situation, because this study was done with the poor people who were mostly uneducated.

Mean age at marriage in our study about ${ }^{17,18}$ years. Same has been reported by PDHS3. Contraceptive use is less in our study supporting the work of others $^{18}$. Commonly used contraceptives were OCP, Injectable and tubectomy which is different from the work of seema at $\mathrm{el}^{7}$ while supported the work of Solomon Avidime et al19. No use of emergency contraceptive method reflects the illiteracy level and knowledge regarding this method. In contrast, $32 \%$ practices of this method have been reported from Ethiopia ${ }^{20}$.

The 3rd major side effects after menstrual irregularities and weight changes was the feeling of guilt with the use of contraceptives which reflects their religious opinion regarding contraception. Learned and authentic scholars should play their role to clarify the minds.

Multipara, older, working and educated woman of this study practiced contraceptives mostly, which is in the line of other study ${ }^{22}$. Current contraceptive use $31 \%$ which is comparable to other studies ${ }^{10-12}$. but lesser than rate reported by Shirmeen et al from Karachi ${ }^{23}$. Though it is more than double the rate observed by Adeniran et $\mathrm{al}^{24}$. Relationship of low CPR with poverty and literacy is well documented fact. Our results confirmed this fact which further supported the work of Shabana and Martin Boabak ${ }^{16}$ and consistent with most of the literature from South Asia and elsewhere ${ }^{25-28}$. Desire for more children, pressure from husband and religion were the main reasons for the non users reflecting the culture, historical background and typical male dominant society of Bangladesh.

The higher level of husband education did not affect the usage of contraceptive significantly $(p=0.92)$ in our study which contradicts the work of Tasnim and Rana Ejaz ${ }^{12}$. Having more sons was another important cause for the nonusers as also reported by others ${ }^{12}$. Religion has been identified to play a significant role in decision to use contraception. Muslims tends to have higher disapproval rate for contraception ${ }^{28}$. Therefore religious scholars should be involved to make it clear that family planning is not sinful and rather beneficial to them.

Positive correlation was observed between age, parity and contraceptive practices which are similar to other study. Husband education is the most dominant determinant for the use of contraceptive in the work of others ${ }^{18}$ though no statistically significant difference was noted in our study.

Community practices and cultural beliefs play significant role in decision making vital to women's reproductive health. For example, certain aspects of our culture strongly discourage the use of modern contraceptives. They believe that those who use modern family planning methods are interfering with nature and they may be punished with infertility on reincarnation. Same has been reported by Lawrence in 2009 from Nigeria ${ }^{21}$.

\section{Conclusion}

Frequency of contraceptive use was comparatively low among the rural married women despite high level of awareness. Desire for larger family, pressure from the husband, religious concerns and fear of side effects were the main reasons that contribute to contraceptive non-use and be addressed as per recommendation of the study findings.

\section{Recommendations}

Considering the findings of the present study, the recommendations are as follows:

- Mass awareness about the benefit of small family and use of contraceptive of choice should be encouraged.

- All family planning and health educators should be equipped with educational and motivational facilities.

- Religious scholars must play their role in clarifying the aspects related to non-use of contraceptives.

- Intensive motivation and awareness is needed for the non users towards use of Condom and Oral pills in particular. 


\section{References}

1. AH Surayakantha, Community Medicine with recent advances, 2nd edition, Jaypee publishers, New Delhi, India-2010.

2. Population References Bureau 2010, World Population Data Sheet. www.prb.org/pdf10/10 world data sheet.pdf.

3. Bangladesh Bureau of Statistics. Preliminary report 2001. Population Census of Bangladesh; 2002.

4. Report of Sample Vital Registration System (SVRS). Bangladesh Bureau of Statistics (BBS), Dhaka; 2004.

5. Effects of the Productive Role of Bangladeshi Women. Reported by Rebecea Sealand Katrina Manson. The Daily Independence. 13 March, 2009.

6. Ministry of Health \& Family Welfare (MOHFW). Population and Development ; Post ICPD, Achievement and Challenges in Bangladesh. Prepared for special session of the UN General Assenmbly. UN,NY, June 30-July 02.1999.

7. Family Planning World Wide Data Sheet, 2002. Washington DC. Population References Bureau, 2002.

8. Reproductive Health Indicator-Guidelines for their generation, interpretation and analysis for global monitoring.Geneva. WHO. Department of Reproductive Health and Research 2006.

9. Population Reference Bureau 2009, World Population Data Sheet.www.prb.org/pdf09/09 world data sheet .PDF.

10.Bibi S, Memon A, Memon Z. Contraceptive knowledge and practices in two districts of Sindh Pakistan-A hospital based survey.JPMA 2008; 58:254-7.

11. US Bureau of the Census, International Brief, World Population at a glance: 1998 and beyond, Washington DC: US. Government Printing office, 1999.

12. Khan T, Khan REA. Fertility behavior of women and their house hold characteristics- A case study of Punjab Pakistan. J Hum Ecol 2010;30:11-7.

13. Agha $\mathrm{S}$. Intentions to Use Contraceptives In Pakistan: Implication for behavior change campaign. BMC public health 2010; 10:450.

14. Takkar N, Goel P, Saha P K, et al. Contraceptive Practices and Awareness ofEmergency Contraception in Educated Working Women. India $\mathbf{J}$ Med Sci 2005;59:143-9.

15. Baldwin SB, Solorio R, Washington DL, et al .Who is using emergency contraception? Awareness and use of emergerncy contraception among California women and teens. Women Health Issues 2008;18: 360-68.
16. Saleem S, Bobak M. Women's Autonomy, Education and Contraception use in Pakistan: A national study. Reproductive Health 2005;2:8.

17. Inamullah H, Sarwar M, Khan N, et al. Attitude of Religious Class toward contemporary female higher education. International Business and Economic Research Journal special edition 2010;9:11-6.

18. Sexna S, Soakeshott P, Hilton S. Contraceptive use amongst south Asian women attending general practices in London. Br J Gen Prac 2001;52:392-4.

19. Avidime S, Aku-Akai L, Mohammad AZ, et al. Fertility intentions, contraceptive awareness and contraceptive use among women in three communities in Northern Nigeria. Afr J Rep Health 2010(special issue); 14:56-70.

20. Worku H, Teklu S. Knowledge, attitude and practices of emergency contraception among drug dispensers working in Addis Ababa. Ethiopia Med J 2011;49:7-15

21. Omo-Aghoja LO, Omo-Aghoja VW, Aghoja CO, et al. Factors associated with the knowledge, practice and perceptions of contraception in rural southern Nigeria. Ghana Medical Journal 2009;44: 115-21.

22. Noyes RA. Contraception and women over 40 years of age: mixed method systematic review. Journal of advancing nursing 2009;65:1155-70.

23. Shirmeen A, Khan MFH, Khan KH, et al. Assessment of fertility control efforts in a selected area of Karachi, Pakistan. Ulster Med J 2007;76:144-5.

24. Adeniran BAO, Adevole IF, Umoh AV, et al. Community based study on contraceptive behaviour in Nigeria. Afr J of Rep Health 2006;10:90-1048.

25. Hamid S, Rob S. Provider and Health Facility Influences on Contraceptive Adoption in Urban Pakistan.International Family Planning Perspective 2006;32:71-8

26. Fikree FF, Khan A, Kadi MM, et al. What influences contraceptive use among young women in urban sqatter settlement of Karachi, Pakistan? International Family Planning Perspective 2001; 27:130-6.

27. Riyamia AL, Afifi M, Mabry RM. Womens' autonomy, education and employment in Oman and their influence on contraceptive use.Reprod Health Matters 2004;12:144-54.

28. Donate S, Hamam R, Medda E. Family planning KAP Survey in Gaza.Soc Sci Med 2000;50:841-9. 